\title{
Исследование мемристорного эффекта в нанокристаллических пленках ZnO
}

\author{
(C) В.А. Смирнов ${ }^{1}$, Р.В. Томинов ${ }^{1}$, В.И. Авилов ${ }^{1}$, Н.И. Алябьева ${ }^{2}$, 3.Е. Вакулов ${ }^{1}$, \\ Е.Г. Замбург ${ }^{1}$, Д.А. Хахулин ${ }^{1}$, О.А. Агеев ${ }^{1}$
}

${ }^{1}$ Южный фредеральный университет,

Институт нанотехнологий, электроники и приборостроения,

347922 Таганрог, Россия

${ }^{2}$ University of Paris-Sud,

Orsay cedex, France

E-mail: vasmirnov@sfedu.ru

(Получена 25 июня 2018 г. Принята к печати 6 июля 2018 г.)

\begin{abstract}
Представлены результаты экспериментальных исследований мемристорного эффекта и влияния режимов отжига на электрофизические свойства нанокристаллических пленок оксида цинка, полученных методом импульсного лазерного осаждения. Показана возможность получения нанокристаллических пленок оксида цинка методом импульсного лазерного осаждения в широком диапазоне электрических (удельное сопротивление от $1.44 \cdot 10^{-5}$ до $8.06 \cdot 10^{-1} \mathrm{OM} \cdot \mathrm{cm}$ ) и морфологических (шероховатость от $0.43 \pm 0.32$ до $6.36 \pm 0.38$ нм) параметров, за счет использования послеростового отжига в атмосфере кислорода (давление $10^{-1}$ и $10^{-3}$ Торр, температура 300 и $800^{\circ} \mathrm{C}$, длительность от 1 до $\left.10 ч\right)$ ). Показано, что нанокристаллическая пленка оксида цинка толщиной $58 \pm 2$ нм проявляет стабильный мемристорный эффект, слабозависящий от ее морфологии - приложение напряжения -2.5 и +4 В приводит к переключению между состояниями с сопротивлением $3.3 \pm 1.1 \cdot 10^{9}$ и $8.1 \pm 3.4 \cdot 10^{7}$ Ом соответственно. Полученные результаты могут быть использованы при разработке конструкций и технологических процессов изготовления элементов резистивной памяти на основе мемристорного эффекта, а также приборов опто-, микро-, наноэлектроники и наносистемной техники.
\end{abstract}

DOI: 10.21883/FTP.2019.01.46991.8941

\section{1. Введение}

Одной из наиболее перспективных разновидностей устройств памяти является резистивная память RRAM, к основным достоинствам которой относятся энергонезависимость, высокое быстродействие, малые размеры ячейки, а также низкое энергопотребление [1-3]. В основе работы RRAM лежит мемристорный эффект, суть которого заключается в изменении сопротивления тонкой оксидной пленки $\left(\mathrm{TiO}_{2}, \mathrm{NiO}, \mathrm{Al}_{2} \mathrm{O}_{3}, \mathrm{HfO}_{2}, \mathrm{SnO}_{2}, \mathrm{WO}_{3}\right.$, $\mathrm{SiO}_{2}$ и др.) при приложении внешнего электрического поля выше порогового значения. По значению сопротивления выделяют два состояния пленки: состояние с бо́льшим сопротивлением (HRS) и состояние с меньшим сопротивлением (LRS) [4-9].

Оксид цинка $(\mathrm{ZnO})$ является одним из наиболее перспективных материалов для создания элементов энергонезависимой резистивной памяти (RRAM) [4-6], что обусловлено его электрофизическими свойствами: широкой запрещенной зоной, химической стабильностью высокими теплопроводностью и температурой плавления, пьезо- и пироэффектами, биологической совместимостью и т. д. [7].

Одной из проблем применения $\mathrm{ZnO}$ для изготовления элементов RRAM является несовместимость технологии получения пленок монокристаллического $\mathrm{ZnO}$ и технологии кремниевой микроэлектроники. Решение этой проблемы возможно при использовании нанокристаллических пленок.
Нанокристаллические пленки оксида цинка могут быть получены несколькими методами: молекулярно-лучевой эпитаксией, химическим осаждением из газовой фазы, магнетронным распылением, золь-гель методом, термическим испарением и импульсным лазерным осаждением [2]. Импульсное лазерное осаждение (ИЛО) является одним из наиболее перспективных методов, так как благодаря большому набору технологических параметров позволяет получать структуры с контролируемыми в широком диапазоне параметрами: нанокристаллические и монокристаллические пленки, нановискеры, нанотетраподы и др. [8]. Кроме того, метод ИЛО совместим с основными методами технологии микроэлектроники.

Для решения задачи изготовления мемристорных структур на основе выращенных методом ИЛО нанокристаллических пленок $\mathrm{ZnO}$ необходимо исследовать влияние наноразмерной структуры пленки на мемристорный эффект и его равномерность.

Для этих целей может быть использована атомносиловая микроскопия (АСМ), которая позволяет проводить исследования локальных электрических свойств поверхности с высоким пространственным разрешением, а также формировать наноразмерные структуры наноэлектроники, микро- и наносистемной техники методами зондовой нанолитографии [10-12].

Цель работы состоит в исследовании мемристорного эффекта в нанокристаллических пленках $\mathrm{ZnO}$, полученных методом импульсного лазерного осаждения; а 
также в исследовании влияния послеростового отжига в атмосфере кислорода на морфологию и удельное сопротивление пленок $\mathrm{ZnO}$ методом атомно-силовой микроскопии.

\section{2. Методика эксперимента}

Экспериментальные образцы были изготовлены на модуле импульсного лазерного осаждения (Pioneer 180, Neocera Co., США) многофункционального нанотехнологического комплекса НАНОФАБ НТК-9 (НТ-МДТ, Россия). Пленки $\mathrm{ZnO}$ были получены испарением мишени металлического Zn с чистотой 99.99\% (KurtLesker Co., США) в атмосфере кислорода, при давлении в камере от $1 \cdot 10^{-1}$ и $1 \cdot 10^{-3}$ Торр. Ocaждение пленок $\mathrm{ZnO}$ проводилось на ситалловые подложки при температурах 300 и $800^{\circ} \mathrm{C}$. Для испарения использовались 50000 импульсов эксимерного лазера $\mathrm{KrF}$ с длиной волны 248 нм и энергией 285 мДж. После осаждения полученные пленки отжигались в атмосфере кислорода при давлении 160 Торр, температуре $750^{\circ} \mathrm{C}$ и длительности 1, 5 и 10 ч. Исследование морфологии поверхности экспериментальных образцов проводилось методом АСМ с помощью зондовой нанолаборатории Ntegra (НТ-МДТ, Россия).

Исследование структуры пленок проводилось с использованием PЭМ Nova NanoLab 600 (FEI Co., Нидерланды), системы регистрации дифракции отраженных высокоэнергетических электронов (RHEED), входящей в состав модуля ИЛО, а также с помощью рентгеновского дифрактометра Rigaku Miniflex 600 (Rigaku Corporation, Япония) (рис. 1).

Измерение удельного сопротивления пленок $\mathrm{ZnO}$ проводилось методом Холла с использованием системы HMS-3000 (Ecopia Corp., Корея).

Результаты экспериментальных исследований морфологии и удельного сопротивления представлены в таблице.

Для исследования мемристорного эффекта в пленках $\mathrm{ZnO}$ были изготовлены экспериментальные структуры: в едином вакуумном цикле на подложку ситалла наносился слой титана толщиной 300 нм, затем формировалась пленка $\mathrm{ZnO}$ толщиной $58 \pm 2$ нм при температуре подложки $300^{\circ} \mathrm{C}$ и давлении $1 \cdot 10^{-1}$ Торр.

Исследования мемристорного эффекта в нанокристаллических пленках $\mathrm{ZnO}$ проводились на воздухе с использованием зондовой нанолаборатории Ntegra. В качестве нижнего контакта использовалась пленка Ті, в качестве верхнего контакта был использован кантилевер марки NSG 20 с проводящим покрытием из Pt. Для исследования равномерности мемристорного эффекта в контактном режиме АСМ-спектроскопии проводились измерения вольт-амперных характеристик (BAX) структуры $\mathrm{Ti} / \mathrm{ZnO} / \mathrm{Pt}$ при приложении напряжения от -2.5 до +4 В в 30 точках вдоль линии на поверхности пленки $\mathrm{ZnO}$ (рис. 2, $a, b$ ). По полученным результатам были определены значения сопротивлений HRS и LRS
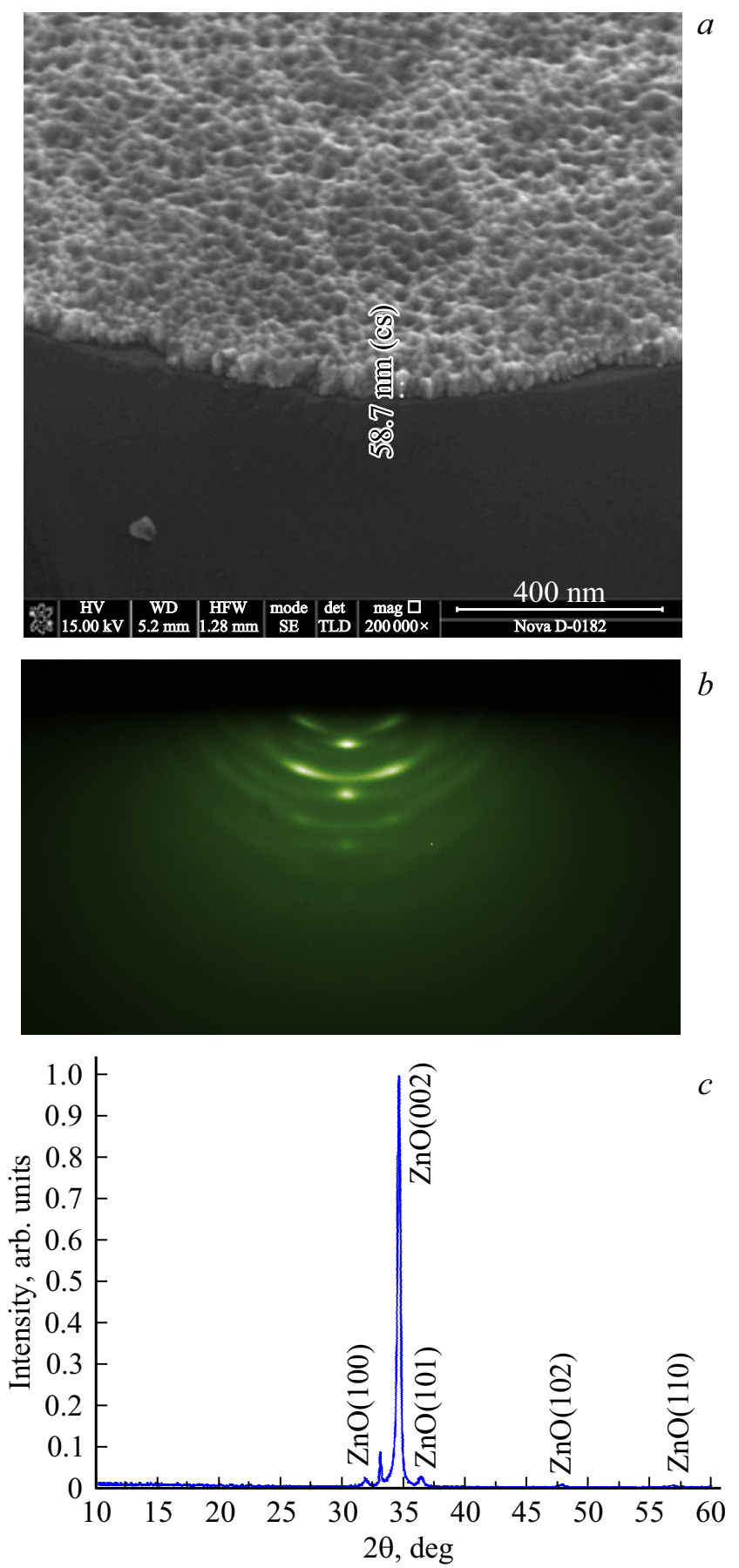

Рис. 1. Пленка ZnO: $a$ - PЭМ-изображение, $b-$ RHEEDизображение, $c-\mathrm{XRD}$-спектр.

при напряжении чтения +1 В (рис. 2,c) и построена усредненная по 30 точкам BAX структуры $\mathrm{Ti} / \mathrm{ZnO} / \mathrm{Pt}$ (рис. 3).

Также для исследования мемристорного эффекта в нанокристаллической пленке $\mathrm{ZnO}$ была разработана методика с использованием токовой АCM, которая заключалась в сканировании двух областей на поверхности $\mathrm{ZnO}$ при напряжениях различной полярности (рис. 4). Формирование области 1 проводилось путем сканирова- 
Параметры нанокристаллических пленок $\mathrm{ZnO}$

\begin{tabular}{|c|c|c|c|c|c|}
\hline \multicolumn{2}{|c|}{ Параметры получения } & \multirow{2}{*}{$\begin{array}{c}\text { Длительность } \\
\text { отжига, ч. }\end{array}$} & \multirow{2}{*}{$\begin{array}{c}\text { Шероховатость } \\
\text { до отжига, нм }\end{array}$} & \multirow{2}{*}{$\begin{array}{c}\text { Шероховатость } \\
\text { после отжига, нм }\end{array}$} & \multirow{2}{*}{$\begin{array}{c}\text { Удельное сопротивление } \\
\text { после отжига, Ом · см }\end{array}$} \\
\hline $\begin{array}{c}\text { Температура } \\
\text { подложки, }{ }^{\circ} \mathrm{C}\end{array}$ & $\begin{array}{c}\text { Давление } \\
\text { кислорода, Торр }\end{array}$ & & & & \\
\hline \multirow{2}{*}{300} & $1 \cdot 10^{-3}$ & $\begin{array}{r}1 \\
5 \\
10\end{array}$ & $1.86 \pm 0.32$ & $\begin{array}{l}1.12 \pm 0.38 \\
1.09 \pm 0.33 \\
0.98 \pm 0.32\end{array}$ & $\begin{array}{l}3.32 \cdot 10^{-5} \\
1.44 \cdot 10^{-5} \\
1.14 \cdot 10^{-1}\end{array}$ \\
\hline & $1 \cdot 10^{-1}$ & $\begin{array}{r}1 \\
5 \\
10\end{array}$ & $1.57 \pm 0.37$ & $\begin{array}{l}0.69 \pm 0.32 \\
0.44 \pm 0.35 \\
0.43 \pm 0.32\end{array}$ & $\begin{array}{l}8.82 \cdot 10^{-3} \\
2.20 \cdot 10^{-2} \\
2.50 \cdot 10^{-1}\end{array}$ \\
\hline \multirow{2}{*}{800} & $1 \cdot 10^{-3}$ & $\begin{array}{r}1 \\
5 \\
10\end{array}$ & $6.45 \pm 0.33$ & $\begin{array}{l}6.36 \pm 0.38 \\
4.09 \pm 0.36 \\
1.99 \pm 0.33\end{array}$ & $\begin{array}{l}8.89 \cdot 10^{-5} \\
7.01 \cdot 10^{-4} \\
8.06 \cdot 10^{-1}\end{array}$ \\
\hline & $1 \cdot 10^{-1}$ & $\begin{array}{r}1 \\
5 \\
10\end{array}$ & $4.96 \pm 0.31$ & $\begin{array}{l}2.01 \pm 0.35 \\
1.78 \pm 0.36 \\
1.24 \pm 0.33\end{array}$ & $\begin{array}{l}5.07 \cdot 10^{-3} \\
5.44 \cdot 10^{-2} \\
1.42 \cdot 10^{-1}\end{array}$ \\
\hline
\end{tabular}

ния поверхности $10 \times 10$ мкм при подаче на зонд напряжения $-2.5 \mathrm{~B}$ (рис. $4, a$ ). Для создания второй области внутри скана $10 \times 10$ мкм проводилось сканирование поверхности $6 \times 6$ мкм при приложении напряжения $+4 \mathrm{~B}$ (рис. 4, b).

После формирования областей по описанной методике поверхность нанокристаллической пленки $\mathrm{ZnO}$ была исследована методом АСМ в полуконтактном режиме (рис. 5,a), режиме отображения сопротивления растекания, при приложении к системе зонд-подложка постоянного напряжения $+1 \mathrm{~B}$ (рис. $5, b)$, и в режиме зонда Кельвина (рис. 5, $c, d$ ).

\section{3. Результаты и их обсуждение}

Анализ РЭМ-изображения поверхности пленки $\mathrm{ZnO}$ показал, что пленка имеет нанокристаллическую структуру (рис. 1,a), что подтверждается результатами RHEED и дифрактометрии. Постоянная решетки определялась при проведении RHEED (рис. 1,b) с использованием специальной программы kSA-400 и составила 0.26 нм. Из анализа дифрактограммы (рис. 1,c) следует, что в пленке $\mathrm{ZnO}$ преобладают кристаллиты ориентации (002) и в значительно меньшей степени присутствуют кристаллиты (100), (101), (102) и (110).

Анализ полученных данных, представленных в таблице, показывает, что после проведения отжига шероховатость поверхности нанокристаллических пленок $\mathrm{ZnO}$ уменьшается. Увеличение давления кислорода от $1 \cdot 10^{-3}$ до $1 \cdot 10^{-1}$ Торр при осаждении пленок при температуре подложки $300^{\circ} \mathrm{C}$ без проведения дополнительного отжига приводит к уменьшению шероховатости поверхности от $1.86 \pm 0.32$ до $1.57 \pm 0.37$ нм, а при температуре подложки $800^{\circ} \mathrm{C}$ без проведения дополнительного отжига приводит к уменьшению шероховатости поверхности от $6.45 \pm 0.33$ до $4.96 \pm 0.31 \mathrm{Hм}$.
С увеличением длительности отжига при температуре подложки $300^{\circ} \mathrm{C}$ шероховатость при давлении $1 \cdot 10^{-3}$ Торр уменьшалась от $1.12 \pm 0.38$ до $0.98 \pm 0.32$ нм и при давлении $1 \cdot 10^{-1}$ Торр уменьшалась от $0.69 \pm 0.32$ до $0.43 \pm 0.32$ нм. С увеличением длительности отжига при температуре подложки $800^{\circ} \mathrm{C}$ шероховатость при давлении $1 \cdot 10^{-3}$ Торр уменьшалась от $6.36 \pm 0.38$ до $1.99 \pm 0.33$ нм и при давлении $1 \cdot 10^{-1}$ Торр уменьшалась от $2.01 \pm 0.35$ до $1.24 \pm 0.33 \mathrm{Hм}$.

С увеличением длительности отжига при температуре подложки $300^{\circ} \mathrm{C}$ удельное сопротивление при давлении $1 \cdot 10^{-3}$ Торр увеличивалось от $3.32 \cdot 10^{-5}$ до $1.14 \cdot 10^{-1} \mathrm{OM} \cdot \mathrm{cm}$ и при давлении $1 \cdot 10^{-1}$ Торр увеличивалось от $8.82 \cdot 10^{-3}$ до $2.50 \cdot 10^{-1} \mathrm{OM} \cdot \mathrm{cm}$. С увеличением длительности отжига при температуре подложки $800^{\circ} \mathrm{C}$ удельное сопротивление при давлении $1 \cdot 10^{-3}$ Торр увеличивалось от $8.89 \cdot 10^{-5}$ до $8.06 \cdot 10^{-1}$ Ом $\cdot$ см и при давлении $1 \cdot 10^{-1}$ Торр увеличивалось от $5.07 \cdot 10^{-3}$ до $1.42 \cdot 10^{-1} \mathrm{OM} \cdot \mathrm{cм}$.

Анализ результатов измерения удельного сопротивления нанокристаллических пленок $\mathrm{ZnO}$ показал, что, изменяя режимы отжига, можно получать пленки с удельным сопротивлением в диапазоне от $1.44 \cdot 10^{-5}$ до $8.06 \cdot 10^{-1} \mathrm{OM} \cdot \mathrm{cm}$.

Данные эффекты связаны с влиянием давления кислорода и температуры отжига на стехиометрию и концентрацию вакансий кислорода в $\mathrm{ZnO}$ [13]. При возрастании температуры отжига и давления кислорода в пленках $\mathrm{ZnO}$ уменьшается концентрация дефектов кристаллической структуры - межузельных атомов цинка или вакансий кислорода, которые являются донорами, способными к двойной ионизации, при этом уменьшается концентрация носителей заряда и увеличивается удельное сопротивление пленки $\mathrm{ZnO}$ [13]. 

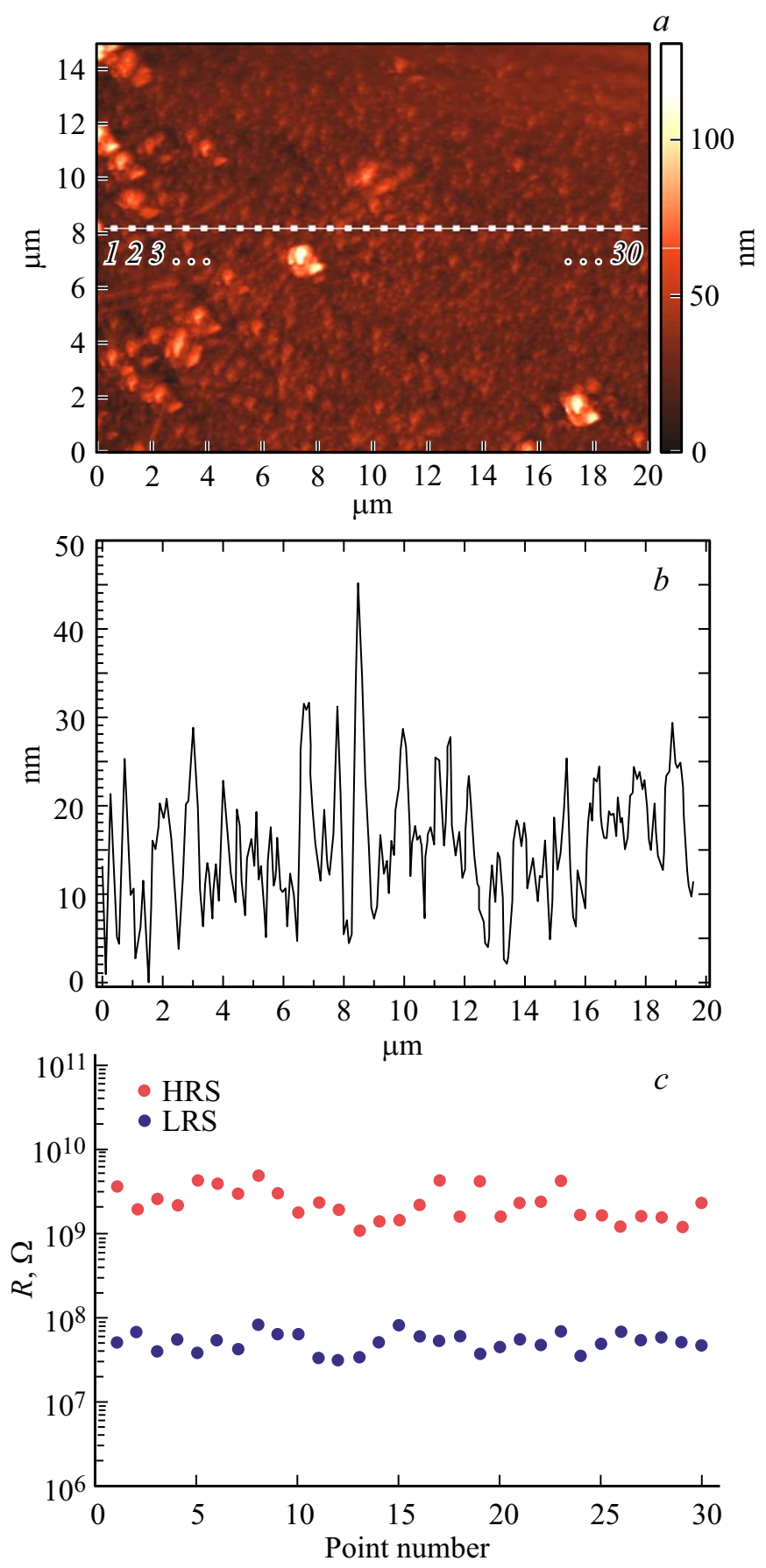

Рис. 2. Результаты исследования равномерности мемристорного эффекта в нанокристалличской пленке $\mathrm{ZnO}: a-$ АСМ-изображение, $b-$ профилограмма вдоль линии на $(a)$, $c-$ сопротивления HRS и LRS в точках вдоль линии на $(a)$.

Анализ усредненной вольт-амперной характеристики (рис. 3) структуры $\mathrm{Ti} / \mathrm{ZnO} / \mathrm{Pt}$ показал, что при приложении напряжения $-2.5 \mathrm{~B}$ пленка $\mathrm{ZnO}$ переключалась в состояние HRS с сопротивлением $3.3 \pm 1.1 \cdot 10^{9} \mathrm{OM}$, a при напряжении +4B нанокристаллическая пленка $\mathrm{ZnO}$ переключалась в состояние LRS с сопротивлением $8.1 \pm 3.4 \cdot 10^{7}$ Ом.
Анализ показал, что значения сопротивлений HRS и LRS в разных точках на поверхности нанокристаллической пленки $\mathrm{ZnO}$ (рис. 2,c) отличаются в пределах порядка и не связаны с особенностями морфологии нанокристаллической пленки $\mathrm{ZnO}$ (рис. 2, $b$ ).

Анализ литературных данных показал, что существует несколько механизмов мемристорного эффекта в оксидах металлов $[4,5,14,15]$. Для объяснения результатов исследований мемристорного эффекта в структуpe $\mathrm{Ti} / \mathrm{ZnO} / \mathrm{Pt}$, представленных в данной работе, можно использовать механизм, связанный с формированием наноразмерных каналов проводимости $[14,15]$. Согласно этому механизму, при приложении внешнего электрического поля дефекты в пленке формируют наноразмерные каналы проводимости, приводящие к переходу окисла из

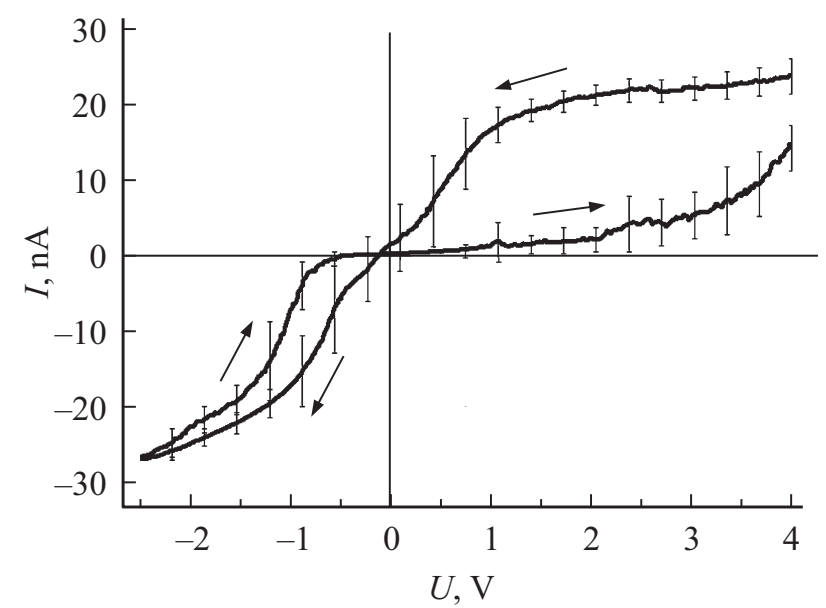

Рис. 3. Вольт-амперная характеристика структуры Ti/ZnO/Pt.

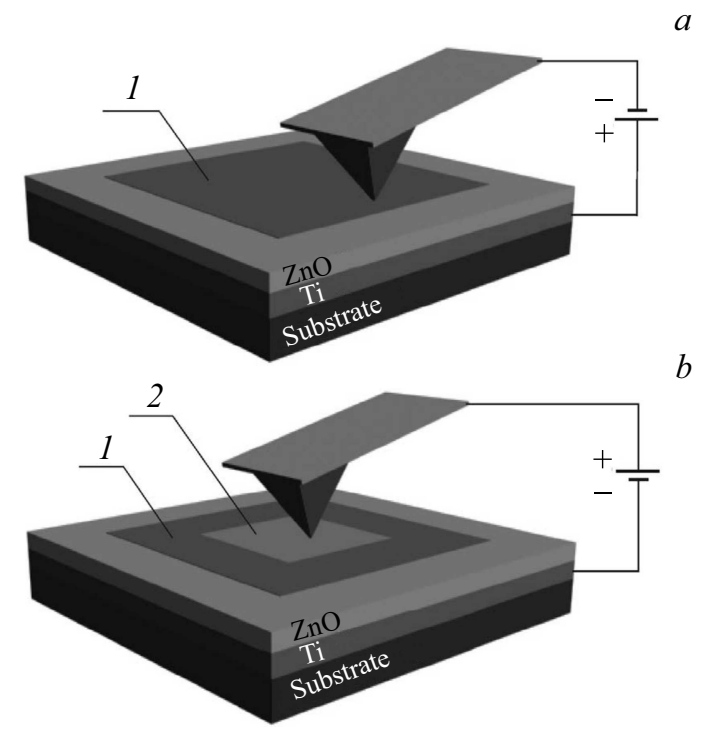

Рис. 4. Схема методики формирования областей LRS и HRS на поверхности нанокристаллической пленки $\mathrm{ZnO}$ при приложении на зонд напряжения: $a-$ отрицательного (область 1 ); $b$ - положительного (область 2). 

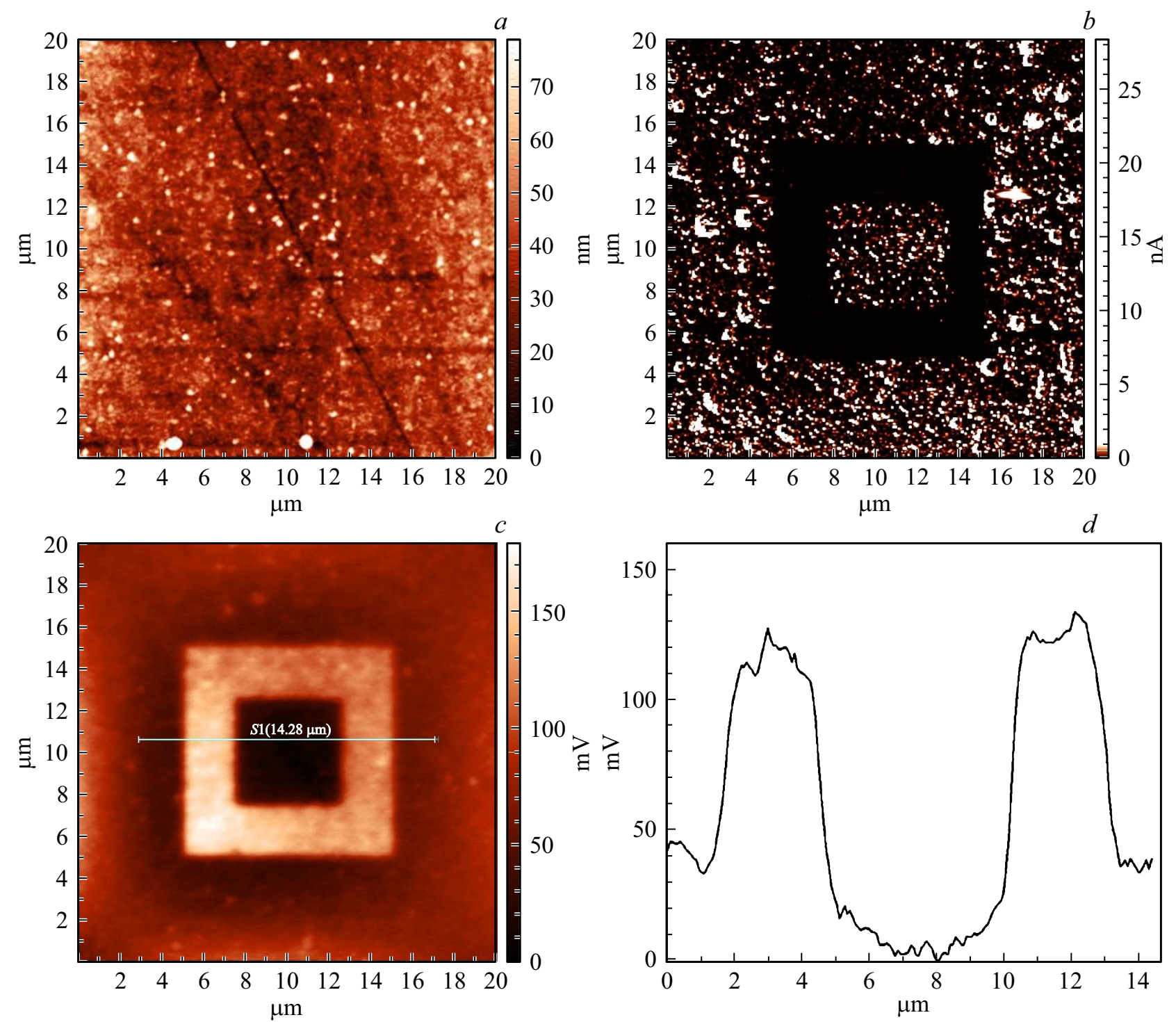

Рис. 5. АСМ-изображение поверхности пленки ZnO: $a-$ морфология, $b-$ токовый контраст, $c-$ распределение потенциала, $d-$ профилограмма вдоль линии на $(b)$.

высокоомного состояния в низкоомное. При приложении внешнего электрического поля противоположной по отношению к первоначальной полярности наноразмерные каналы проводимости разрываются за счет теплового воздействия [15].

Анализ полученных экспериментальных результатов отображения сопротивления растекания показал (рис. $5, b)$, что исходной пленке $\mathrm{ZnO}$ соответствует низкоомное состояние (светлый контраст). Согласно разработанной методике (рис. 4), после сканирования области поверхности пленки $\mathrm{ZnO}$ площадью $10 \times 10$ мкм $^{2}$ при напряжении зонд-подложка $-2.5 \mathrm{~B}$ на поверхности была сформирована квадратная область с высоким сопротивлением (темный контраст), внутри которой путем сканирования области площадью $6 \times 6$ мкм $^{2}$ при напряжении зонд-подложка +4В была сформирована квадратная область с низким сопротивлением (светлый контраст). Формирование областей с низким и высоким сопротивлением свидетельствует о возникновении мемристорного эффекта в нанокристаллической пленке $\mathrm{ZnO}$.

Анализ АСМ-изображения поверхности пленки $\mathrm{ZnO}$ (рис. 5, $a$ ) и карты отображения сопротивления растекания (рис. 5, $b$ ) показывает наличие на поверхности пленки частиц материала, слабо проводящего ток. Это можно объяснить особенностями процесса импульсного лазерного осаждения. При высокой плотности мощности лазерного излучения распыление мишени происходит неравномерно с образованием не только отдельных атомов и молекул, но и крупных частиц материала с меньшей проводимостью, которые также осаждаются на поверхность подложки [16]. Этот эффект может быть устранен при оптимизации режимов импульсного лазерного осаждения. 
Из анализа АCM-изображения структуры на поверхности пленки $\mathrm{ZnO}$, полученной методом Зонда-Кельвина (рис. 5,c), видно, что более высокое значение поверхностного потенциала было получено при приложении отрицательного потенциала к зонду (рис. $5, d$ ), при этом формируется область с высоким сопротивлением, на которой происходит накопление заряда. При формировании области с низким сопротивлением значение поверхностного потенциала уменьшается, что хорошо коррелирует с литературными данными $[17,18]$.

\section{4. Заключение}

Показана возможность контролируемого получения нанокристаллических пленок $\mathrm{ZnO}$ методом ИЛО в широком диапазоне электрических и морфологических параметров: удельное сопротивление от $1.44 \cdot 10^{-5}$ до $8.06 \cdot 10^{-1} \mathrm{OM} \cdot \mathrm{cm}$, шероховатость от $0.43 \pm 0.32$ до $6.36 \pm 0.38$ нм. Показано, что нанокристаллическая пленка $\mathrm{ZnO}$ толщиной $58 \pm 2$ нм, полученная методом импульсного лазерного осаждения, проявляет стабильный мемристорный эффект, слабозависящий от ее морфологии. При приложении напряжения $-2.5 \mathrm{~B}$ пленка переключалась в высокоомное состояние с сопротивлением $3.3 \pm 1.1 \cdot 10^{9}$ Ом, при приложении напряжения +4 В пленка $\mathrm{ZnO}$ переключалась в низкоомное состояние с сопротивлением $8.1 \pm 3.4 \cdot 10^{7}$ Ом.

Полученные результаты могут быть использованы при разработке конструкций и технологических процессов изготовления элементов резистивной памяти на основе мемристорных структур, а также приборов опто-, микро-, наноэлектроники и наносистемной техники.

Исследование выполнено при финансовой поддержке РФФИ в рамках научных проектов № 16-3200069 мол_а, Совета по грантам президента РФ (проект № МК-2721.2018.8) и Южного федерального университета (проекты № ВнГр-07/2017-02, ВнГр-07/2017-26). Результаты получены с использованием оборудования Научно-образовательного центра „Нанотехнологии“ и Центра коллективного пользования Южного федерального университета.

\section{Список литературы}

[1] D. Strukov, G. Snider, D. Stewart. Nature, 453, 80 (2008).

[2] B. Chagaan, P. Wolfgang, R. Tamas. Cellular Nanoscale Sensory Wave Computing, 1st edn (US, Springer, 2010).

[3] C. Kügeler, R. Rosezin, E. Linn. Appl. Phys., 102, 791 (2011).

[4] W.Y. Chang, Y.C. Lai, T.B. Wu. Appl. Phys. Lett., 92, 022110 (2008).

[5] Y. Zhang, Z. Duan, R. Li, C.J. Ku. Appl. Phys., 46, 145101 (2013).

[6] O. Ageev, E. Zamburg, D. Vakulov, Z. Vakulov, A. Shumov, M. Ivonin. Appl. Mechanics and Materials, 475, 446 (2014).

[7] C. Jagadish, S. Pearton. Zinc Oxide Bulk, Thin Films and Nanostructures Processing, Properties, and Applications (Elsevier, 2006).
[8] O. Ageev, D. Golosov, E. Zamburg, A. Alexeev, D. Vakulov, Z. Vakulov, A. Shumov, M. Ivonin. Appl. Mechanics and Materials, 481, 55 (2014).

[9] V. Avilov, O. Ageev, A. Kolomiitsev, V. Smirnov, O. Tsukanova. Semiconductors, 48 (13), 1757 (2014).

[10] B. Bhushan. Springer Handbook of Nanotechnology (Springer, 2010).

[11] O. Ageev, B. Konoplev, V. Smirnov. Semiconductors, 44 (13), 1703 (2010).

[12] O. Ageev, B. Konoplev, V. Smirnov. Russian Microelectronics, 36 (6), 353 (2007).

[13] A. Janotti, C. Walle. Phys. Rev., 76, 165202 (2007).

[14] B.J. Choi, D.S. Jeong, S.K. Kim, C. Rohde, S. Choi. J. Appl. Phys., 98, 033715 (2005).

[15] N. Xu, L. Liu, X. Sun, X. Liu, D. Han. Appl. Phys. Lett., 92, 232112 (2008).

[16] M.Z. Lin, C.T. Su, H.C. An. Jpn. J. Appl. Phys., 44 (31), 995 (2005).

[17] M.H. Lee, K.M. Kim, S.J. Song. Appl. Phys. A, 102, 827 (2011).

[18] O. Ageev, Y. Blinov, O. Ilin, A. Kolomiitsev, B. Konoplev, M. Rubashkina, V. Smirnov, A. Fedotov. Techn. Phys., 58 (12), 1831 (2013).

Редактор Г.А. Оганесян

\section{Investigation of memristor effect in nanocrystalline $\mathrm{ZnO}$ films}

V.A. Smirnov ${ }^{1}$, R.V. Tominov ${ }^{1}$, V.I. Avilov ${ }^{1}$, N.I. Alyabieva ${ }^{2}$, Z.E. Vakulov' ${ }^{1}$, E.G. Zamburg ${ }^{1}$, D.A. Khakhulin ${ }^{1}$, O.A. Ageev ${ }^{1}$

${ }^{1}$ Southern Federal University, Institute of Nanotechnologies,

Electronics and Electronic Equipment Engineering, 347922 Taganrog, Russia

${ }^{2}$ University of Paris-Sud,

Orsay cedex, France

Abstract This work represents theoretical and experimental investigations of resistive switching effect and annealing regimes influence in nanocrystalline $\mathrm{ZnO}$ films, grown by using pulsed laser deposition. The nanocrystalline $\mathrm{ZnO}$ films can be obtained in wide range electrical (resistivity: $1.44 \cdot 10^{-5}-8.06 \cdot 10^{-1} \Omega \cdot \mathrm{cm}$ ) and morphological (roughness: $0.43 \pm 0.32-6.36 \pm 0.38 \mathrm{~nm}$ ) parameters due to a postgrowth annealing in oxygen (pressure: $10^{-1}, 10^{-3}$ Torr; temperature: $300,800^{\circ} \mathrm{C}$; annealing time: 1,5 , $10 \mathrm{~h}$ ). It is shown, the nanocrystalline $\mathrm{ZnO}$ film with a thickness $58 \pm 2 \mathrm{~nm}$ has a stable resistive effect switching. Morphology has a slight effect on resistive effect switching. Applying voltage between -2.5 and $+4 \mathrm{~V}$ results to $\mathrm{ZnO}$ film resistance switching between $3.3 \pm 1.1 \cdot 10^{9}$ and $8.1 \pm 3.4 \cdot 10^{7} \Omega$, respectively. The results can be useful for RRAM manufacturing based on $\mathrm{ZnO}$ thin films, also for opto-nano and nanosystem techniques. 